\title{
The Interplay of the Local Microbiome with Oral Mucosal Immune Compartment: Minireview
}

\author{
Ibrahim Mohamed Saeed Shnawa \\ College of Biotechenology, University of Qasim, Qasim, Babylon, Iraq
}

\section{Email address:}

ishnawa@yahoo.com

To cite this article:

Ibrahim Mohamed Saeed Shnawa. The Interplay of the Local Microbiome with Oral Mucosal Immune Compartment: Minireview. American Journal of Biomedical and Life Sciences. Special Issue: Advances in Oral Immunity. Vol. 3, No. 4-1, 2015, pp. 17-19.

doi: $10.11648 / j$.ajbls.s.2015030401.16

\begin{abstract}
The oral microbiome is formed and functioned in balanced state during health and in an unbalanced state in the disease conditions. Microbiome in the oral compartment combats the weapons of the invading microbial pathogens. Now, there are a specific microbiome signature in each of the cases of health and disease. Oral microbiome expressed; probiotic, antigenic competition and immunomodulatory effects locally in the oral compartment .In the immunologic sense, oral microbiome is constituting an element that is able to interact in a bidirectional fashion with the components of the oral immune compartment with the net result of homiostasis, immune response ,tolerance, anergy and hypersensitivity and/or immune mediated diseases. Thus it has played an important roles in oral immune mechanisms.
\end{abstract}

Keywords: Anergy, Antigenic Competition, Hypersensitivity, Immune, Response, Mucosa, Microbiome Oral

\section{Introduction}

Found in human oral cavity have been assigned as an oral microflora, oral microbiome ,and oral micrbiota(1).Such microbiome influences an interplay with the elements and events for both of the mucosal and systemic immune responses (2).Since it may cause diseases through several biological mechanisms like; synergism, antagonism, as well as the initiation of immune suppression mechanisms $(3,4,5,6,7,8,9)$. The objective of the present mini review is to relate microbiome to the elements of the oral immune compartment and their involved immune mechanisms.

\section{Microbiome}

Food, drink, and suck together with swallowing are the basic sources of mouth invasion by various microbes and parasites $(10,11,12)$. The oral microbiome includes both cultivable and in-cultivable micro-flora .Both of which may be categorized into ;major, minor and transient fractions. Such microbiome is composed of; Commensals, opportunistics, principle human pathogen and at times unsuccessful animal pathogens. To investigate such microbiomes, several attitudes have been followed (13 ), like conventional aerobic, microaerophilic, and anaerobic cultivation methods as well as the molecular DNA ,PCR technique and 16 S RNA methods. The identification can be done by manual,API20E, and Vitek methodologies for culturable microflora. In-culturable microflora can be assessed through the use of molecular techniques. These microflora can be grouped into; procaryota, archae and eucaryotes $(10,11,12,13,14,15)$.The formed elements of the oral human microbiome, Table 1, 2, appeared within the mouth cavity forming parts as bio-films. Oral cavity contains more than 600 different species .There were a signature microbiomes for; health ,gingivitis, periodontitis, as well as oral cancer diseases $(5,9)$

Table 1. Human Oral Microbiome, cultivable and non-cultivable flora ( adapted from, 11).

\begin{tabular}{lll}
\hline Major Fraction & Minor Fraction & Transient Fraction \\
\hline St.salivarus & Anaerobic cocci & St.pyogenes \\
St.sanjuis & St.pneumoniae & S.aureus \\
St.mutans & Staphylococci & N.meningiditis \\
St.milleri & Fusobacterium & C.diphtheriae \\
St.mitis & Borrelia & Protozoa \\
Corynebacterium sp. & Treponema & Viruses \\
Branhamella catahrralis & Campylobacter & \\
Haemophilus & Mycoplasma & \\
Veilonella spp. & Candida spp. & \\
Lactobacillus spp. & Nocardia & \\
Leptospira spp. & & \\
Bacteroids spp. & & \\
Eikenella & & \\
\hline
\end{tabular}


Table 2. Cultivable microbiome as a rate of isolation from oral different topographies( Adapted from,11).

\begin{tabular}{lllll}
\hline Oragnisms & Gingival cervix & Dental Plaque & Tongue & Saliva \\
\hline Streptococci & 27.1 & 27.9 & 38.3 & 41.0 \\
St.salivarius & - & - & 8.2 & 4.6 \\
$\begin{array}{l}\text { Staphylococci } \\
\text { Gram positive }\end{array}$ & 1.7 & 0.3 & 6.5 & 4.0 \\
$\begin{array}{l}\text { Anaerobic cocci } \\
\text { Gram negative }\end{array}$ & 7.4 & & & \\
Anaerobic cocci & 10.7 & 12.5 & 4.2 & 3.0 \\
$\begin{array}{l}\text { Gram positive rods } \\
\text { Gram positive }\end{array}$ & 15.3 & 6.4 & & \\
Anaerobic rods & 20.2 & 27.8 & 16.0 & 15.9 \\
Gram negative & & 18.4 & & 11.8 \\
Anaerobic rods & 16.1 & 10.4 & 8.2 & 4.8 \\
\hline
\end{tabular}

\section{Oral Immune Compartment}

The anatomic topography of the oral compartment includes ; gingival surface, dontium, periodotium, tongue , salivary glands as well as tonsils(10). Two types of immune barriers are found in the oral cavity. The mechanical covers ; the salivary flow ,swallowing reflex ,tongue movement teeth morphology and keratinized mucosa .While the immunobiological barrier are SIgA and mucosal bactericidins $(10,11,12)$.It was worth-mentioning that there were several events do happened on the epithelial surfaces like glycolysis ,membrane balance and microbial antagonisms .Beside which there were salivary defenses like salivary lysozymes ,cervicular exudates ,lactoferrin, polymophonuclear ,mononuclear leukocytes $(16,17,18)$.

The oral tissues constitute a resident and migratory immune cells like; macrophages ,dendritic cells, langerhans cells as well as natural killer cells, B lymphocyte and T lymphocytes. The immune stimulation both on the local and systemic levels for the immune committed lymphocytes will produces antibodies and cytokines .The crevicular surface contains $\operatorname{IgG}$, IgA , IgM , while salivary gland does contain $\operatorname{Ig} \mathrm{A}, \operatorname{SIg} \mathrm{A}, \operatorname{IgG}$ and $\operatorname{IgM}(16,17,18)$.

\section{Oral Immune Balance Versus Imbalance}

In normal healthy mouth, components of the oral microbiome are in a balance state $(1,2,3,4,5,6,7,8,9)$, while in the disease, ,there were an imbalance state between the weapons of the of the oral pathogens and the local defense machinery, which of them overweight the capabilities of the other, it will prevails then the disease do happened ,if not, human host mouth will restores its own balance state ( 12 )

\section{The Interplay}

In general, host and his own microbiome have coevoloved. The immune system shaped the microbiome. Microbiome in turn, impacts the immune system development such as the formation of organized lymphoid tissue in mucosal immune system and the development of CD4,T reg, Th17 in the systemic immune system(16).

The periodontal diseases and caries were associated with marked degree of the oral microbiome complexity .The composition of this microbiome differs from one intra-oral site to another reflecting impart the nature of host immune response and the immune capacity(17)

There were metabolic and immunologic interactions between the oral microbiome and the host epithelial surfaces , and it is thought to be of bidirectional, nature. The oral microbial colonization is more than a friendly coexistence, it represents a complex ecosystem with an inborn implication for human metabolic haemiostasis , and immune tolerance(18).

Microbiome may exhibits direct antagonistic anti-pathogen effects .The commensal part may showed probiotic effect ( 19,20, 21 ),towards the anchorments effect of the pathogen. Quorum sensing (QSS) substances(12) may be secreted from the microbiome which in turn may expresses an immunomodulatory effects on the oral immune effector cells. The mediators and the antigens of the oral microbiome may act as anergizing or tolerizing roles to the local immune functioning cells like oral dendritic ,B,T cells.

The epitope nature of the oral microbiome, in the sense of antigenicity and immunogenicity, it is rather considered as a huge combinations of chemically heterogenous antigenic epitopes that might be of different types(linear,topographic etc...).Such combinations may expresses a competitive(Inter and intra-molecular competition )effects among each other on facing the local immune committed cells. The net results will be either augmentation or dampening action of the local immune responses .If the oral microbial pathogens run faster in the competition on trigger of immune cells ,the situation becomes rather complex. The more immunodominant epitope whatsoever its nature will trigger the oral immune cells to be enrolled in immune mechanisms( 22 ).

In view of the aforementioned information the collective seen of the local immune mechanisms in the oral immune compartment are ;mucosal immune responses ,mucosal immune tolerance ,mucosal immune silencing and/or hypersensitivity $(16,17,18,19,2021,22,23,24)$.Therefore in the immunologic sense the oral microbiome holds the position of an element that is able to interact with the components of the oral immune compartment with the net results of homiostasis, immune response, tolerance and /or hypersensitivity Table 3 .

Table 3. The Possible Immune Potentials of Oral Microbiome.

\begin{tabular}{l}
\hline 1-Probiotic Effects \\
2-Immunomodulatory Effects through either humoral or cellular factors \\
3-Toleragenic Effects \\
4-Anergizing Effects \\
5-Intrinsic Immunologic adjuvanicity \\
6- Allergenic Effects \\
7-Antigenic Competitive Effect \\
8- Immune mediated tissue injuries. \\
\hline
\end{tabular}




\section{Oral Microbiome Versus Disease}

Recently ,workers have been documenting certain microbiome signatures for health, gingivitis, periodontitis, carries, oral cancers as well as systemic oriented cancers $(23,24)$.

\section{Immune Simulation}

Oral murine microbiome can translocate to placenta. Pooled saliva and gingival plaque samples were injected in mouse tail vein to mimic bacterimia which occur frequently during periodontitis. The microbial species colonizing placenta were detected using 16SRNA gene based PCR and clone analysis .It was obvious that the majority of which were oral commensals, this also may indicate a unique role of commensal species in causing uterine infections(25).Fardinr and his coworkers(26) have shown that the transmission of oral microbiome to placenta if the principle source of the intrauterine infections. In other experiment in murine model, it was proved that adaptive immune response modulate the composition of the microbiome in oral cavity and in rectum but not in the skin in a steady state fashion (27).

\section{Conclusions}

Commensals, opportunistic ,pathogen as well as unsuccessful animal pathogens are forming elements of oral microbiome. It is balanced in health state and unbalanced in disease state. There are specific microbiome signature for health and disease. It combates the pathogenic weapon of the oral invading microbes .Its immune interplay can be through antigenic competition ,immunomodulation, probiotic effects.

\section{References}

[1] Dewhirst FE,Chen T, Pasker BJ , Tunner ARC, Yu W-H , Lackshmanan A, Wade WG,2010,The human oral microbiome, J Bacteriol.192(10):5002-5017.

[2] He J , Li Y,Cao Y, Xue J, Zhou X, 2015, The oral microbiome diversity and its relation to human diseaselia. Microbiol., 60:69-80.

[3] Wade WG,2013, Oral microbiome in health and disease,Pharmacol.Res.69(1):137-143.

[4] Eren AM,Borisy GG, Huse SM,Welch JLM ,2014,Oligotyping analysis of the human microbiome, Proc. Nat. Acad. Sci. USA, 111(128) :2875-2884.

[5] Liu B, Faller LL, Klitgord A, Mazumdar V, et al,2012,Deep sequencing of oral micrbiome reveals signature of periodontal dieasese PLOs one 7(6);37919.

[6] Scannapieco F A ,2013, The oral micrbiome its role in health and in oral and systemic disease,Clin.Micrbiol.Newslett 35(20):163-169.

[7] Kumar PB, Manson MR,2015,Mouthguards,the endogenous microbiome play a role in maintaining oral health ,Front. Cell. Infect. Microbiol. ,May 2015
[8] Zaura E, Maria A,2015, The oral microbiome in an ecological perspectives ,Front .Cell .Infect. Micrbiol.,April,2015

[9] McLean J S ,2014,Advancements towards systems level of the human micrbiome, Frot .Cell. Infect. Microbiol., July ,2014

[10] Samaranayake LP, Jones BM,2002,Essential Microbiology for Dentistry $2^{\text {nd }}$ ed., Churchill-livingstone, Edinburgh ,205-252.

[11] Ross PW ,1979,Infections of the mouth, In Ross, PW, Clinical Bacteriology, Churchill-Livingstone ,Medical texts, Edinburg, 81-88.

[12] Brooks G F, Caroll KC,Butel JS,Morse SA,Mietzner TA 2013,Jawetz,Melnick And Adelbergs Medical Microbiology,26 ${ }^{\text {th }}$ ed.,Lange McGraw-Hill,New York, 165.

[13] Thwaini QNT, ALZamely O M Y, AlFadhili, A Z M 2015.Aerobic and Aerotolerant Bacterial profile of Halitosis, Am. J. Biomed.Life.Sci.3(4):

[14] Aller T, Mevarech M,2005,Archeal genetics-The third way, A review, Nature Genetics 6:58-72.

[15] Olsen GJ, Woese CR, 1997,Archeal genomics: An overview ;Mini review ,Cell, 89,991994.

[16] Fraser CM,2013,The interplay between the gut microbiota and the immune system, NHGRI symposium, April 25,2013.

[17] Costalonga M, Herzberg MC,2014,The oral microbiome and the immunobiology of dental diseases and caries,Immunol.Lett.,162(2):22-38.

[18] Pfefferle PI, Renz H,2014,The mucosal microbiome in shaping health disease,F1000 Prime. Rep. 6:11

[19] Shnawa IMS,2015,Mucosal Immune tolerance versus Oral immune silencing, Am.J .Biomed .Life Sci.3(4):7-9.

[20] Walker DM,2004,Oral mucosal immunology ,An overview, Ann .Acad. Sigapore 33:275-303.

[21] Novak N, Haberstok J Bieber T, Allam J P ,2008, The immune privileged of the oral mucosa,Cell,14(5):192-198.

[22] Shnawa IMS, Mehdi MS,2004,Mucosal Agglutinating antibodies of the antigens of the bacteria associated with urinary tract infections in adults, Kufa Med.J,7(1):237-244.

[23] Kerr AR ,2015, The oral microbiome and cancer, Dental hygiene, 89 (S 1):20-23.

[24] Dominique M,Jaques I,2014,Microbiota,oral microbiome and Pancreatic cancer,Can .J.,20:203-206.

[25] Ashton Acton Q,2011,Coordination of toleragenic immune responses by commensal microbota, Issues In Immunology Research, Scholary edition, USA.

[26] Fardinr and colleagues,2010,transmission of oral microbiota is a principle source of intrauterine infection, Infect. Immun. ,78(4):1798-1796.

[27] Scholz F, Badgley BD, Sadowsky MJ, Kaplan DH, 2014, Immune mediated shaping of microflora composition depends on barrier site, Plose one Jan 8,2014 . 